\title{
Methemoglobin and nitric oxide therapy in Ugandan children hospitalized for febrile illness: results from a prospective cohort study and randomized double-blind placebo-controlled trial
}

Andrea L. Conroy ${ }^{1,2}$, Michael Hawkes ${ }^{3}$, Kyla Hayford ${ }^{1,2}$, Laura Hermann ${ }^{1}$, Chloe R. McDonald ${ }^{2,4}$, Suparna Sharma², Sophie Namasopo ${ }^{5}$, Robert O. Opoka ${ }^{6}$, Chandy C. John ${ }^{7}$ W. Conrad Liles ${ }^{8}$, Christopher Miller ${ }^{9}$ and Kevin C. Kain ${ }^{1,2,4,10,11^{*}}$

\begin{abstract}
Background: Exposure of red blood cells to oxidants increases production of methemoglobin (MHb) resulting in impaired oxygen delivery to tissues. There are no reliable estimates of methemoglobinemia in low resource clinical settings. Our objectives were to: i) evaluate risk factors for methemoglobinemia in Ugandan children hospitalized with fever (study 1); and ii) investigate MHb responses in critically ill Ugandan children with severe malaria treated with inhaled nitric oxide (iNO), an oxidant that induces $\mathrm{MHb}$ in a dose-dependent manner (study 2).

Methods: Two prospective studies were conducted at Jinja Regional Referral Hospital in Uganda between 2011 and 2013. Study 1, a prospective cohort study of children admitted to hospital with fever (fever cohort, $n=2089$ children 2 months to 5 years). Study 2, a randomized double-blind placebo-controlled parallel arm trial of room air placebo vs. 80 ppm iNO as an adjunctive therapy for children with severe malaria (RCT, $n=180$ children $1-10$ years receiving intravenous artesunate and $72 \mathrm{~h}$ of study gas). The primary outcomes were: i) masimo pulse co-oximetry elevated MHb levels at admission (>2\%, fever cohort); ii) four hourly MHb levels in the RCT.

Results: In the fever cohort, $34 \%$ of children admitted with fever had elevated MHb at admission. Children with a history of vomiting, delayed capillary refill, elevated lactate, severe anemia, malaria, or hemoglobinopathies had increased odds of methemoglobinemia ( $p<0.05$ in a multivariate model). MHb levels at admission were higher in children who died $(n=89)$ compared to those who survived $(n=1964), p=0.008$. Among children enrolled in the iNO RCT, MHb levels typically plateaued within 12-24 h of starting study gas. MHb levels were higher in children receiving iNO compared to placebo, and $\mathrm{MHb}>10 \%$ occurred in $5.7 \%$ of children receiving iNO. There were no differences in rates of study gas discontinuation between trial arms.
\end{abstract}

Conclusions: Hospitalized children with evidence of impaired oxygen delivery, metabolic acidosis, anemia, or malaria were at risk of methemoglobinemia. However, we demonstrated high-dose iNO could be safely administered to critically ill children with severe malaria with appropriate MHb monitoring.

\footnotetext{
*Correspondence: kevin.kain@uhn.ca

'Depatment of Medicine, University of Toronto, Toronto, Canada

${ }^{2}$ Sandra A. Rotman Laboratories, Sandra Rotman Centre for Global Health,

University Health Network-Toronto General Hospital, University of Toronto,

Toronto, Canada

Full list of author information is available at the end of the article
} 
(Continued from previous page)

Trial registration: ClinicalTrials.gov Identifier: NCT01255215 (Date registered: December 5, 2010).

Keywords: Pediatrics, Methemoglobin, Inhaled nitric oxide, Malaria, Anemia, Metabolic acidosis, Oxygen delivery, Fever, Uganda

\section{Background}

An estimated 200 million malaria infections occur every year, resulting in an estimated 1.2 million deaths [1], the majority of which are attributable to Plasmodium falciparum infection. Despite the availability of effective artemisinin-based antimalarial therapies, mortality rates remain high in severe malaria (8-20\% in children), suggesting that therapies targeting the parasite alone are insufficient in individuals with established manifestations of severe disease. One potential strategy to reduce mortality rates is to identify adjunctive therapies that target deleterious host immune responses (reviewed in [2, 3]). The endothelium, acting as a 'biosensor', is increasingly being recognized as a critical regulator of vascular integrity in life-threatening infections characterized by systemic inflammation, like sepsis and severe malaria, and therefore represents a promising target for adjunctive therapy [4].

One strategy to promote endothelial integrity is to increase bioavailable nitric oxide (NO), a gaseous free radical produced by the conversion of L-arginine to $\mathrm{L}$ citrulline through a family of nitric oxide synthase enzymes [5]. A number of human studies have reported associations between reduced bioavailable NO and malaria disease severity [6-8]. Preclinical data from an experimental model of cerebral malaria (CM) reported improved survival, reduced systemic inflammation and endothelial activation, and retained blood-brain-barrier integrity following administration of iNO $[9,10]$. iNO is approved for human use (5-80 ppm), and is routinely used in North America and Europe for the treatment of persistent pulmonary hypertension or infant respiratory distress syndrome in term or near-term neonates $[11,12]$. Based on these data, we sought to evaluate whether iNO would improve clinical recovery when administered in adjunct to standard anti-malarial therapy in a cohort of children with severe malaria $[13,14]$.

As iNO is systemically absorbed it combines with hemoglobin to form nitrosylhemoglobin, which is then oxidized to form methemoglobin (MHb) [15]. MHb is formed by oxidation of ferrous iron $\left(\mathrm{Fe}^{++}\right)$to ferric iron $\left(\mathrm{Fe}^{+++}\right)$within the heme moiety of hemoglobin $(\mathrm{Hb})$, resulting in a functional impairment in the ability of $\mathrm{Hb}$ to transport oxygen and carbon dioxide [16]. As red blood cells (RBCs) are continuously bathed in oxygen, there is constant oxidation of $\mathrm{Hb}$ to $\mathrm{MHb}$, but levels of $\mathrm{MHb}$ typically remain $<1 \%$ due to endogenous reduction systems [17]. Elevated levels of $\mathrm{MHb}(>10 \%)$ can lead to clinical signs of hypoxemia ranging from mild headache to respiratory distress, cyanosis and death with increasing levels of $\mathrm{MHb}$. Although methemoglobinemia typically occurs following ingestion or skin exposure to an oxidizing agent, it can also occur as a result of genetic, dietary or other factors [18].

In this study, we prospectively evaluated MHb levels in Ugandan children hospitalized with fever. Our objectives were three-fold: i) to determine $\mathrm{MHb}$ levels at admission among children hospitalized for febrile illness in Ugandan children; ii) to explore clinical and demographic factors associated with elevated $\mathrm{MHb}$; and iii) to evaluate the safety and tolerability of high-dose inhaled nitric oxide in children with severe malaria using MHb. We assessed the first two objectives in a prospective observational study of 2089 febrile children admitted to hospital in a resource-constrained hospital in Eastern Uganda. The impact of iNO on $\mathrm{MHb}$ was assessed in a randomized double-blind placebo-controlled trial evaluating iNO as an adjunctive therapy for children with severe malaria where iNO was administered at $80 \mathrm{ppm}$ continuously for up to $72 \mathrm{~h}$. Although iNO is routinely administered in neonates at doses of 5-20 ppm, there are limited data on the effect of iNO on $\mathrm{MHb}$ levels at higher doses, and no data from pediatric populations in Africa.

\section{Methods}

Study site

Studies took place at the Jinja Regional Referral Hospital between July 2011 and August 2013 in Jinja, Uganda. The hospital serves a catchment area of 3 million people encompassing 12 districts in mid-eastern Uganda. The children's unit has 100 beds and an average admission rate of 650 children per month. Malaria transmission in the Jinja area is moderate with an estimated entomological inoculation rate of six infective bites per person per year $[19,20]$. Malaria is the most common admission diagnosis in the children's unit.

\section{Study 1 design: prospective in-patient study of children} hospitalized with non-malarial and malarial fever

Children aged 2 months to 5 years were eligible for the study if they had a documented fever or history of fever within the previous $48 \mathrm{~h}$ and were admitted to hospital by the attending physician. Children with diarrheal illness without any other symptoms of systemic infection were excluded from the study. At admission, information 
was collected on patient demographics, history of illness, and treatments. Daily follow-up was conducted by study personnel to determine clinical outcome. Methemoglobin was assessed using a Masimo $\mathrm{SET}^{\bullet} \mathrm{Rad}-57^{\mathrm{Tx}}$ pulse cooximeter (Masimo Corporation, Irvine, CA), by experienced pediatric nurses and medical officers according to standard operating procedures. Malaria infection (lab-confirmed malaria) was defined using microscopy (Field's stained thick blood smear examined by an experienced technician at the Jinja Hospital Laboratory using a light microscope) and/or rapid diagnostic tests (HRP2/pLDH positive or pLDH positive test, First Response MalariaAg. pLDH/HRP2 Combo Rapid Diagnostic Test, Premier Medical Corporation Limited, India) [21].

Study 2 design: randomized double-blind placebo-controlled clinical trial comparing air versus high-dose iNO as an adjunctive therapy for severe malaria

Children aged 1 to 10 years with suspected severe malaria were screened in the emergency department at Jinja Regional Referral Hospital for inclusion in the trial. The trial is registered (ClinicalTrials.gov Identifier: NCT01255215). Children were eligible for the study if they had a positive malaria rapid diagnostic test in the presence of features of severe malaria [13]. After obtaining informed consent, children were randomized to receive either room air or iNO starting at $80 \mathrm{ppm}$ by nonrebreather $\mathrm{HiOx}^{\circ}$ face mask (CareFusion, CA) for $72 \mathrm{~h}$ (or until the child recovered and no longer tolerated the mask). Children were randomized using simple randomization using a computer generated list created by the unblinded team leader (ALC). Group assignment was recorded on a piece of paper and kept in sequentially sealed opaque envelops in a locked cabinet accessible only to un-blinded investigators. Following enrollment, malaria was confirmed using thick and thin Giemsa-stained peripheral blood smears assessed by light microscopy at the Makerere University-John's Hopkins University (MU-JHU) Core Lab, which is a College of American Pathologists certified, quality-controlled central research laboratory in Kampala. All children received parenteral artesunate for severe malaria as described [22]. Children were excluded from the study if they had known chronic illnesses (e.g. renal, cardiac or hepatic diseases, epilepsy, cerebral palsy, clinical AIDS), hemoglobinopathies, severe malnutrition $(<-3 S D$ weight-for-age), severe malarial anemia $(\mathrm{Hb}<50 \mathrm{~g} / \mathrm{L})$ without any other signs of severe malaria, and baseline methemoglobinemia (>2 \%) that did not resolve following patient stabilization.

Study gas (continuous iNO or room air placebo) was administered by an un-blinded research team not involved in patient care including: a trial manager to randomize children and start treatment gas, and a team of un-blinded study nurses to monitor gas delivery and potential toxicities. Study gas was temporarily discontinued if one of the following occurred: $\mathrm{MHb}>10 \%$; elevated inspired $\mathrm{NO}_{2}$ concentration $>5 \%$; persistent hypoxemia; evolving respiratory distress; unexplained tachycardia; unexplained hypotension; any study drug related adverse event that, in the opinion of the investigator, made it unsafe for the subject to continue. Following temporary discontinuation of the study gas, there was the possibility of re-challenge following resolution of the adverse event. Treatment was permanently discontinued if there was refractory methemoglobinemia ( $\mathrm{MHb}$ above $10 \%$ despite re-starting iNO at a lower concentration following temporary discontinuation); hemoptysis; acute kidney injury; any study drug related adverse event that, in the opinion of the investigator, made it unsafe for the subject to continue; any study drug related adverse event requiring temporary discontinuation that recurred on re-challenge at the same or lower dose of iNO; or at the discretion of the subject or guardian; at the discretion of the investigator.

Baseline MHb levels were assessed at time of patient screening and were repeated following randomization. After the study gas was initiated, MHb levels were assessed on a four-hourly basis. Nurses kept detailed clinical record of any time off gas to accurately assess the time children were exposed to iNO.

\section{Statistical analysis}

Data were analyzed using IBM SPSS 20, Stata 13 (College Station, TX) and GraphPad Prism 6. Demographic, clinical and laboratory characteristics of participants at enrolment were described using proportions for binary variables and mean or median values for continuous variables, as appropriate. Age and sex-standardized z-scores for height-for-age, weight-for-age and height-for-weight were calculated using the World Health Organization Anthro program (version 3.2.2, January 2011).

Baseline $\mathrm{MHb}$ levels were analyzed as a percentage or categorized as methemoglobinemia ( $>2 \%$ vs. $\leq 2 \%$ ). Risk factors for methemoglobinemia at admission were evaluated using bivariate and multivariate logistic regression models. Model selection for the multivariate model was based on variables selected a priori (age) and all variables that predicted methemoglobinemia at an alpha level of $\leq 0.2$ in bivariate logistic regression models. Final variable selection for the multivariate model balanced parsimony with model fit based on Hosmer-Lemeshow's goodness of fit test, minimizing Akaike's Information Criteria and Bayesian Information Criteria. Unadjusted and adjusted odds ratios are presented with $95 \%$ confidence intervals.

\section{Results}

Data were analyzed for 2089 children with known outcomes in the pediatric fever cohort (study 1) and 180 
children in the iNO RCT (study 2). Median age was 1 year [IQR: 0,2$]$ in the fever cohort and 2 years $[1,3]$ in the iNO RCT (Table 1). Clinical characteristics at enrollment such as temperature, heart rate, oxygen saturation, capillary refill time and blood pressure were comparable in both cohorts. In the fever cohort (study 1), the median Blantyre coma score (BCS) was 5 [IQR: 5,5], $33 \%$ presented with vomiting and $30 \%$ presented with diarrhea. In the iNO RCT, the median BCS was $2[2,3]$ with 4 and $21 \%$ presenting with vomiting and diarrhea, respectively. Sixty-seven percent of children in the pediatric fever cohort had lab-confirmed malaria (by thick film blood smear or positive RDT pLDH/HRP2 or pLDH alone) compared to $100 \%$ in the iNO RCT, an enrollment criteria for the RCT. Twenty percent and $61 \%$ of fever and iNO RCT cohorts, respectively, had severe anemia (Table 1). Median MHb levels at admission were $1.5 \%$ [IQR: 0.7, 2.6] in the fever cohort and $1.7 \%[1.2,2.1]$ in the iNO RCT cohort $(p>0.05)$. Sixty-two out of 547

Table 1 Characteristics of Study Cohorts

\begin{tabular}{|c|c|c|}
\hline & $\begin{array}{l}\text { Fever Cohort } \\
(n=2089)\end{array}$ & $\begin{array}{l}\text { iNO Trial Cohort } \\
(n=180)\end{array}$ \\
\hline Age, years $^{a}$ & $1[0,2]$ & $2[1,3]$ \\
\hline Male, \% (\#) & $55 \%(1134)$ & $57 \%(102)$ \\
\hline Temperature, ${ }^{\circ} \mathrm{C}$ & $37.9(1.2)$ & $37.9(1.2)$ \\
\hline Heart rate, bpm & $159.2(25.2)$ & $160.7(25.0)$ \\
\hline Systolic BP & $105.0(15.9)$ & $110.5(20.2)$ \\
\hline Diastolic BP & $57.4(13.4)$ & $58.7(13.6)$ \\
\hline Respiratory rate & $44[36,56]$ & $48[38,62]$ \\
\hline Vomiting & $33 \%(686)$ & $4 \%(8)$ \\
\hline Diarrhea & $30 \%(614)$ & $21 \%(38)$ \\
\hline Blantyre coma score & $5[5,5]$ & $2[2,3]$ \\
\hline $\mathrm{SpO} 2$ & $98[96,100]$ & $99[98,100]$ \\
\hline Lactate $(\mathrm{mmol} / \mathrm{L})^{\mathrm{b}}$ & $2.7[1.9,4.9]$ & $3.6[2.1,6.4]$ \\
\hline Lactate $>5 \mathrm{mmol} / \mathrm{L}^{\mathrm{b}}$ & $24 \%(485)$ & $24 \%(43)$ \\
\hline \multicolumn{3}{|l|}{ Capillary refill time } \\
\hline$<2 \mathrm{~s}$ & $85 \%(1724)$ & $82 \%(148)$ \\
\hline $2-3 s$ & $10 \%(194)$ & $12 \%(22)$ \\
\hline$>3 \mathrm{~s}$ & $5 \%(106)$ & $6 \%(10)$ \\
\hline Lab-confirmed malariac ${ }^{c}$ & $67 \%(1240)$ & $100 \%$ \\
\hline Severe anemia $^{d}$ & $20 \%(428)$ & $61 \%(109)$ \\
\hline Pretreatment with antibiotic & $33 \%(682)$ & $43 \%(74)$ \\
\hline Pretreatment with antimalarial & $46.2 \%(956)$ & $59 \%(105)$ \\
\hline
\end{tabular}

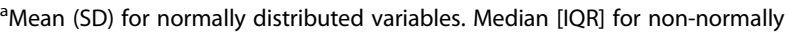
distributed variables. Number (\%) for categorical variables

${ }^{b}$ Lactate was assessed using LactateScout in the fever cohort and i-STAT in the iNO trial as previously described [52]

'Positive by microscopy or RDT (HRP2/pLDH or pLDH)

${ }^{\mathrm{d} S e v e r e ~ a n e m i a ~ d e f i n e d ~ a s ~ h e m o g l o b i n ~ l e s s ~ t h a n ~} 5 \mathrm{~g} / \mathrm{dL}$ (hospital laboratory) or pallor by clinical assessment in the fever cohort and $\mathrm{Hb}<5 \mathrm{~g} / \mathrm{dL}$ (reference laboratory) in the iNO trial cohort
(11.3\%) subjects were excluded from the iNO RCT due to elevated $\mathrm{MHb}$ at admission.

\section{Study 1 cohort: risk factors of elevated $\mathrm{MHb}$ in a pediatric fever cohort}

Among 2089 children admitted to the hospital with a fever (Table 2), 34\% had methemoglobinemia (MHb >2\%), $6 \%$ had MHb levels above 7, and $3 \%$ had MHb levels above $10 \%$. In bivariate analysis, multiple factors differed between children with vs. without methemoglobinemia (Table 2). In a multivariate logistic regression model, children with methemoglobinemia at presentation were significantly more likely to have vomiting (adjusted odds ratio $(\mathrm{aOR}) 1.36,95 \% \mathrm{CI}: 1.09,1.70)$, prolonged capillary refill time (aOR 1.36, $95 \%$ CI: 1.11, 1.66) and elevated lactate levels (aOR 1.08, 95 \% CI: 1.05, 1.11) after controlling for relevant demographic, clinical and laboratory results. The odds ratio of methemoglobinemia was two times higher in children with hemoglobinopathies (sickle cell anemia or glucose-6-phosphate dehydrogenase deficiency (G6PD)) (aOR 1.97, 95 \% CI: 1.17, 3.32), or in severe anemia (aOR 1.99, 95 \% CI: 1.51, 2.61). Children with lab-confirmed malaria (aOR 1.34, $95 \%$ CI: 1.07, 1.69) also had an elevated risk of methemoglobinemia. Of children with lab-confirmed malaria, 54.6\% met WHO criteria for severe malaria, including: prostration, deep breathing, jaundice, hyperlactatemia, hypoglycemia, severe anemia, altered consciousness or hemoglobinuria. $\mathrm{MHb}$ levels were higher in children with severe malaria ( $n=754$; median $1.9 \%$, IQR, 0.8-4.1) compared to uncomplicated malaria $(n=627$; median $1.4 \%$, IQR: $0.7-2.0)$, $p<0.0001$ by Mann-Whitney $\mathrm{U}$ test.

Admission $\mathrm{MHb}$ levels were higher in non-survivors ( $n=89$; median $1.7 \%$, IQR: $0.8-4.6)$ compared to survivors $(n=1964$; median $1.5 \%$, IQR: $0.7-2.5), p=0.008$ (Mann-Whitney U Test). Analysis of missing data showed that $\mathrm{MHb}$ values were more likely to be missing in nonsurvivors compared to survivors at 10.1 and $1.3 \%$ respectively (reflecting the difficulty in getting pulse co-oximetry measurements in critically ill children with poor perfusion).

\section{Study 2 cohort: $\mathrm{MHb}$ levels in children receiving iNO as an adjunctive therapy for severe malaria Overview of trial}

Among children enrolled in the iNO RCT, 92 were randomized to receive placebo (room air) and 88 to receive iNO between July 2011 and June 2013. The mean time on gas was comparable between groups (mean (SD): placebo, 63.6 (19.9) hours; iNO, 61.9 (21.7) hours, $p=0.582$ ). Gas was withdrawn for 31 children (12 children in the placebo arm and 19 in the iNO arm, $p=0.13$ ). 10 children had gas temporarily discontinued for the following reasons: methemoglobin $>10 \%, n=5$; unexplained tachycardia, $n=1$; investigator discretion, $n=4$ (stridor, $n=2$; 
Table 2 Factors associated with methemoglobinemia in a pediatric fever cohort

\begin{tabular}{|c|c|c|c|c|c|c|}
\hline & $\begin{array}{l}\mathrm{MHb} \leq 2 \% \\
N=1364(66 \%)\end{array}$ & $\begin{array}{l}\mathrm{MHb}>2 \% \\
N=689(34 \%)\end{array}$ & $\begin{array}{l}\text { Bivariate OR } \\
(95 \% \mathrm{Cl})\end{array}$ & $P$-value & $\begin{array}{l}\text { Multivariate OR } \\
(95 \% \mathrm{Cl})\end{array}$ & $P$-value \\
\hline \multicolumn{7}{|l|}{ Demographic characteristics } \\
\hline Age, months & $17[9,26]$ & $18[9,30]$ & $1.00(1.00,1.01)$ & 0.268 & $1.00(1.00,1.01)$ & 0.370 \\
\hline Age $<6$ months & $98(7.2)$ & $53(7.7)$ & $1.08(0.76,1.52)$ & 0.677 & & \\
\hline Male (\%) & $734(54.4)$ & $382(56.1)$ & $1.07(0.89,1.29)$ & 0.461 & & \\
\hline \multicolumn{7}{|l|}{ Clinical findings at admission } \\
\hline Fever $\left(\geq 38^{\circ} \mathrm{C}\right)$ & $402(39.1)$ & $276(27.6)$ & $0.59(0.49,0.72)$ & $<0.001$ & $0.74(0.60,0.92)$ & 0.005 \\
\hline Underweight, $<-2$ WAZ & $303(22.6)$ & $150(22.3)$ & $0.97(0.77,1.21)$ & 0.775 & & \\
\hline Systolic BP & $105.5(15.3)$ & $104.2(7.0)$ & $0.99(0.99,1.00)$ & 0.094 & & \\
\hline Diastolic BP & $58.4(13.3)$ & $55.6(13.4)$ & $0.98(0.98,0.99)$ & $<0.001$ & $0.99(0.98,1.00)$ & 0.130 \\
\hline Age-specific elevated respiratory rate, per min & $693(52.7)$ & $398(59.8)$ & $1.34(1.11,1.62)$ & 0.002 & & \\
\hline Deep breathing & $282(20.7)$ & $213(31.0)$ & $1.72(1.40,2.12)$ & $<0.001$ & & \\
\hline Vomiting & $399(29.3)$ & $272(39.6)$ & $1.58(1.30,1.91)$ & $<0.001$ & $1.36(1.09,1.70)$ & 0.007 \\
\hline Diarrhea & $424(31.2)$ & $176(25.6)$ & $0.82(0.64,0)$. & 0.008 & $0.82(0.64,1.04)$ & 0.107 \\
\hline \multicolumn{7}{|l|}{ Blantyre coma score } \\
\hline $\begin{array}{l}0 \\
1 \\
2 \\
3 \\
4 \\
5\end{array}$ & $\begin{array}{l}21(1.6) \\
13(1.0) \\
22(1.6) \\
45(3.4) \\
63(4.7) \\
1173(87.7)\end{array}$ & $\begin{array}{l}26(3.9) \\
9(1.3) \\
25(3.7) \\
41(6.1) \\
48(8.6) \\
514(76.4)\end{array}$ & $0.78(0.71,0.85)$ & $<0.001$ & & \\
\hline \multicolumn{7}{|l|}{ Capillary refill time } \\
\hline$<2$ seconds & $1180(89.5)$ & $515(77.0)$ & & & & \\
\hline $2-<3 \mathrm{sec}$ & $90(6.8)$ & $102(15.2)$ & & & & \\
\hline$\geq 3 \mathrm{sec}$ & $49(3.7)$ & $49(3.7)$ & $1.81(1.52,2.16)$ & $<0.001$ & $1.36(1.11,1.66)$ & 0.003 \\
\hline Pretreatment with antibiotics & $428(31.6)$ & $240(35.5)$ & $1.19(0.98,1.45)$ & 0.079 & & \\
\hline Pretreatment with sulfadoxine pyremethamine & $16(1.2)$ & $14(2.1)$ & $1.76(0.85,3.63)$ & 0.125 & & \\
\hline Subcostal retractions & $236(17.3)$ & $172(25.0)$ & $1.59(1.27,1.98)$ & $<0.001$ & & \\
\hline \multicolumn{7}{|l|}{ Laboratory test results at admission } \\
\hline Lactate, mmol/L & $2.5[1.8,4.0]$ & $3.4[2.2,8.5]$ & $1.14(1.11,1.16)$ & $<0.001$ & $1.08(1.05,1.11)$ & $<0.001$ \\
\hline Glucose, $\mathrm{mmol} / \mathrm{L}$ & $7.1(2.3)$ & $7.9(3.3)$ & $1.11(1.07,1.15)$ & $<0.001$ & & \\
\hline Oxygen saturation $\left(\mathrm{SpO}_{2}\right)$ & $98[96,100]$ & $98[95,99]$ & $0.97(0.95,0.99)$ & 0.015 & & \\
\hline Severe anemia, $\mathrm{Hb}<5 \mathrm{~g} / \mathrm{dL}$ or pallor & $182(13.3)$ & $233(33.8)$ & $3.32(2.66,4.14)$ & $<0.001$ & $1.99(1.51,2.61)$ & $<0.001$ \\
\hline Suspected hemoglobinopathy & $41(3.0)$ & $41(6.0)$ & $2.04(1.31,3.18)$ & 0.002 & $1.97(1.17,3.32)$ & 0.011 \\
\hline Lab-confirmed malaria ${ }^{1}$ & $883(64.8)$ & $498(72.5)$ & $1.43(1.17,1.74)$ & 0.001 & $1.34(1.07,1.69)$ & 0.011 \\
\hline
\end{tabular}

Mean (SD) for normally distributed variables. Median [IQR] for non-normally distributed variables. Number (\%) for categorical variables 'Positive by microscopy or RDT (HRP2/pLDH or pLDH)

Factors significantly associated with methemoglobinemia in bivariate or multivariate analysis in bold

resuscitation, $n=1$; transfer to another hospital for transfusion, $n=1)$. 21 children had gas permanently discontinued for the following reasons: acute kidney injury, $n=10$; guardian withdrew consent, $n=2$; technical/power issues, $n=2$; mask required for oxygen delivery, $n=1$; recovery/ refusal to tolerate the mask, $n=6$. There were no differences between rates of temporary (placebo, $n=3$ vs. iNO, $n=7 ; p=0.21$ ) or permanent discontinuation (placebo, $n=10$ vs. iNO, $n=12 ; p=0.57$ ) of study gas between trial arms. However, $\mathrm{MHb}>10 \%$ requiring temporary withdrawal of study gas only occurred in children receiving iNO $(n=5,5.7 \%), p=0.026$. Apart from elevated $\mathrm{MHb}$, there were no other study drug-related adverse events listed in the product monograph (hypotension, atelectasis, hematuria, hyperglycemia, sepsis, infection, stridor, cellulitis) [23].

\section{$\mathrm{MHb}$ response to iNO administration}

As this is the largest trial reported to date to administer nitric oxide at $80 \mathrm{ppm}$ (the highest FDA approved dose), 
and methemoglobinemia is a known complication of iNO, we investigated the impact of $80 \mathrm{ppm}$ iNO on $\mathrm{MHb}$ levels. This represents a secondary analysis of the study. The primary efficacy data are presented elsewhere [24]. MHb levels were assessed at scheduled times on a four hourly basis following study gas initiation. The mean time between initiation of study gas and the first gas check was $2.2 \mathrm{~h}$, during which time there was a 2.3 fold-mean increase in $\mathrm{MHb}$ percent among children receiving iNO (mean $\mathrm{MHb}_{\text {Baseline }}=1.8$ to $4.1 \%$ ) but no change in children receiving placebo (mean $\mathrm{MHb}_{\text {Baseline }}$ $=1.7$ to $1.8 \%$ ). Although there was considerable variability in $\mathrm{MHb}$ responses over time, MHb levels typically peaked and plateaued within $12-24 \mathrm{~h}$ of receiving nitric oxide (Fig. 1a). To illustrate the variability in MHb levels over time, representative plots of $\mathrm{MHb}$ levels over hospitalization were generated for a randomly selected subset $(10 \%)$ of study participants $(n=17 ; n=7$ placebo arm, $n=10$ nitric oxide arm) (Fig. 1b). Representative graphs are shown for children who received study gas without interruption $(\mathrm{A}-\mathrm{C})$, children with temporary interruptions to gas flow (D-F), children who had study gas permanently discontinued because of acute kidney injury (G-I), and deaths (J-L) (Fig. 2).

\section{MHb levels in fatal malaria}

In the iNO RCT, we did not observe a significant difference between $\mathrm{MHb}$ levels assessed following randomization and mortality (MHb levels $\leq 2 \%$ at screening was an eligibility requirement), $p=0.071$ by Mann-Whitney $\mathrm{U}$ test. The majority of study deaths occurred in the first $48 \mathrm{~h}$ of hospitalization ( $n=14$ of 16 total deaths; [ $n=8$ in the placebo group, $n=6$ in the iNO group]) with over half of study deaths ( $n=8,57.1 \%)$ occurring before a second $\mathrm{MHb}$ measurement was taken. The mean time from study enrollment to death was $13 \mathrm{~h}$. Because longitudinal data on $\mathrm{MHb}$ levels in non-survivors was limited, we were unable to explore differences in temporal trends in $\mathrm{MHb}$ levels between survivors and non-survivors.
Of children with multiple MHb measurements taken prior to death, there was one case of rising $\mathrm{MHb}$ prior to death. A 1 year old presented to the emergency department with a 3-day history of fever having received pre-referral treatment with chloramphenicol and intravenous quinine. The child was prostrate and comatose (Blantyre coma score $=2$ ) with convulsions, prolonged capillary refill time ( $>3 \mathrm{~s}$ ), jaundice, hypoglycemia, and severe anemia. At presentation, the patient had cough and age-related tachypnea (respiratory rate, $56 / \mathrm{min}$ ) but no other signs of respiratory distress (nasal flaring, deep breathing, subcostal retractions). A diagnosis of severe malaria was made and the patient was treated with intravenous artesunate, dextrose, diazepam and phenobarbitone. Following enrollment in the clinical trial, the child was transferred to the study ward and study gas (room air) was initiated. On arrival to the study ward, the lactate level was $2.3 \mu \mathrm{mol} / \mathrm{L}$ and the $\mathrm{MHb}$ level was $0 \%$. Over the course of several hours, the child deteriorated clinically and developed respiratory distress with nasal flaring and intercostal and subcostal retractions and a progressive decline in Sp02 \% to a nadir of 87 \%. Supplemental oxygen was administered, but $\mathrm{MHb}$ levels continued to rise reaching $9.3 \%$ before death (Fig. 2j). The cause of death was cardiopulmonary arrest.

Among children who died receiving iNO, only one had multiple MHb measurements taken prior to death (Fig. 2l).

\section{Discussion}

In this study, we examined levels of MHb in two cohorts of children presenting to a regional pediatric referral hospital in Eastern Uganda. Although these studies represent distinct patient populations (there was no patient overlap between studies), the subjects were enrolled over the same 2 year period from the same catchment area. Overall, the children enrolled in the fever cohort were younger (according to the study design) and included all
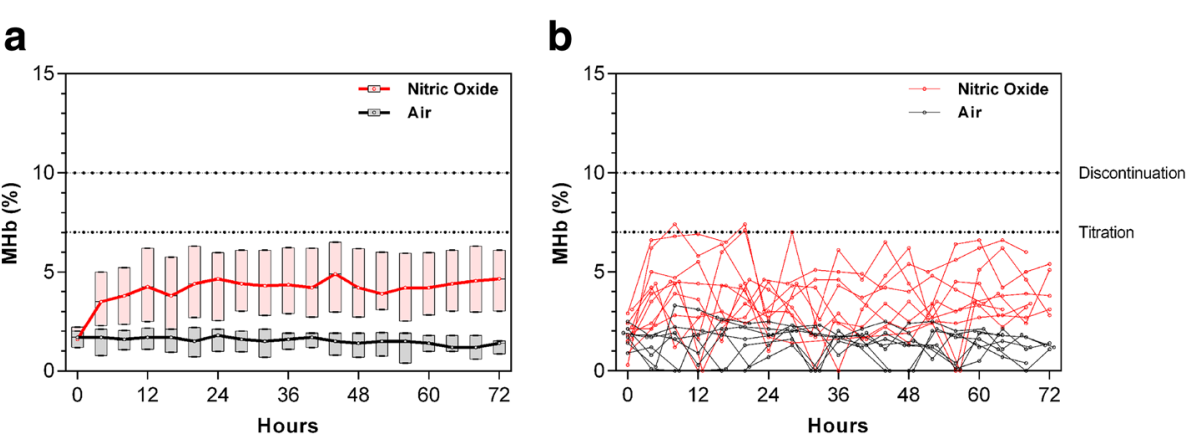

Fig. $1 \mathrm{MHb}$ levels in children with severe malaria randomized to room air or nitric oxide as an adjunctive therapy to intravenous artesunate. a Box and whisker plots showing the median (IQR) and $95 \% \mathrm{Cl}$ for the trial arms at scheduled four hourly MHb checks. b Representative MHb plots for a random subset (10\%) of study participants ( $n=7$ placebo arm, $n=10$ nitric oxide arm) 

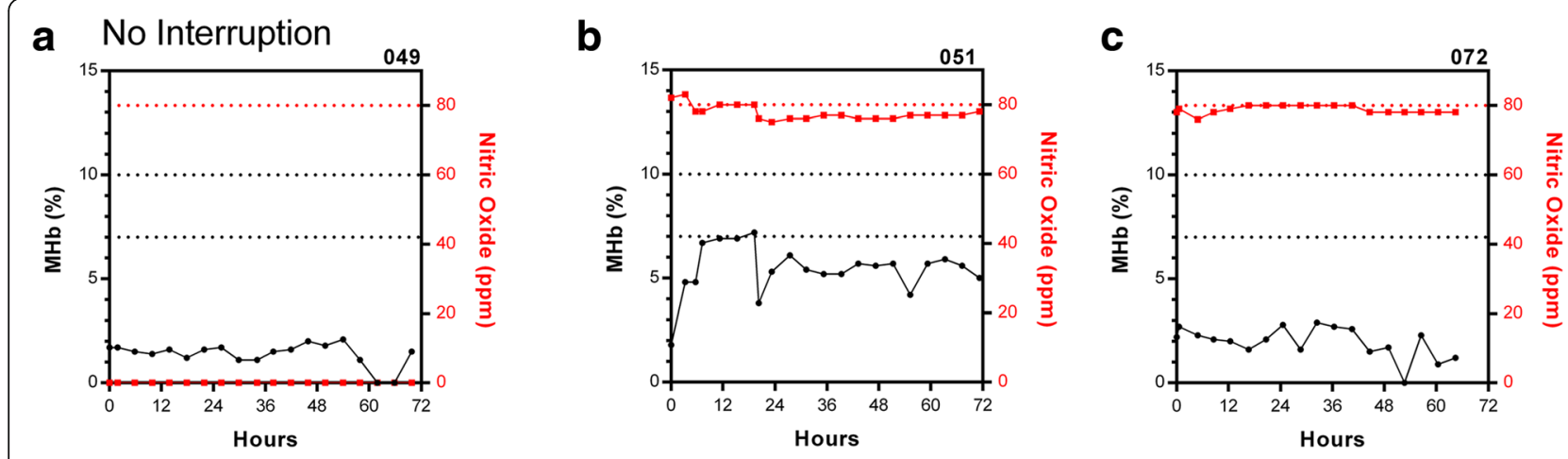

d Temporary Discontinuation
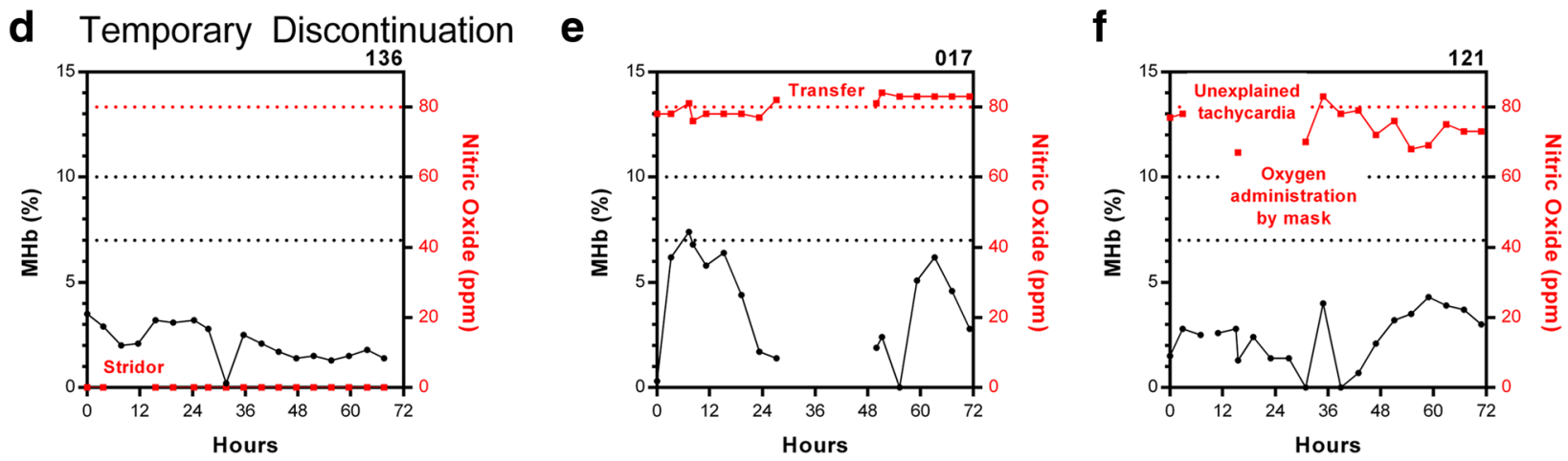

g Permanent Discontinuation

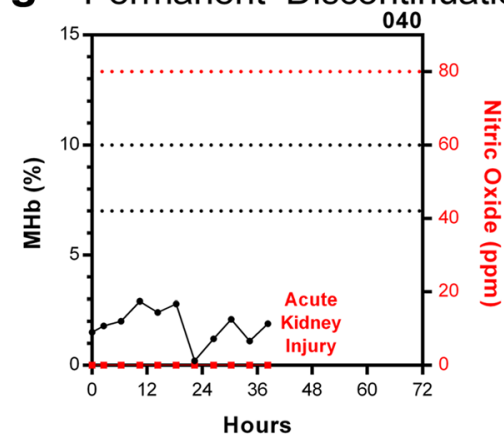

h

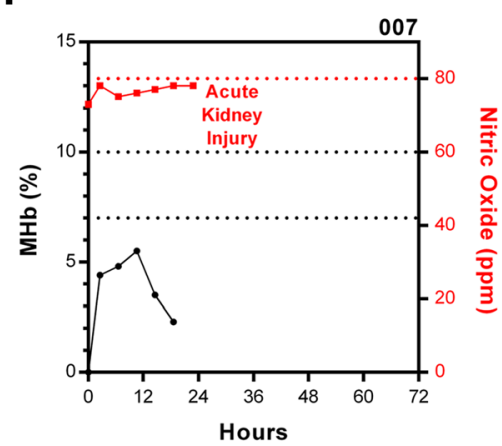

i
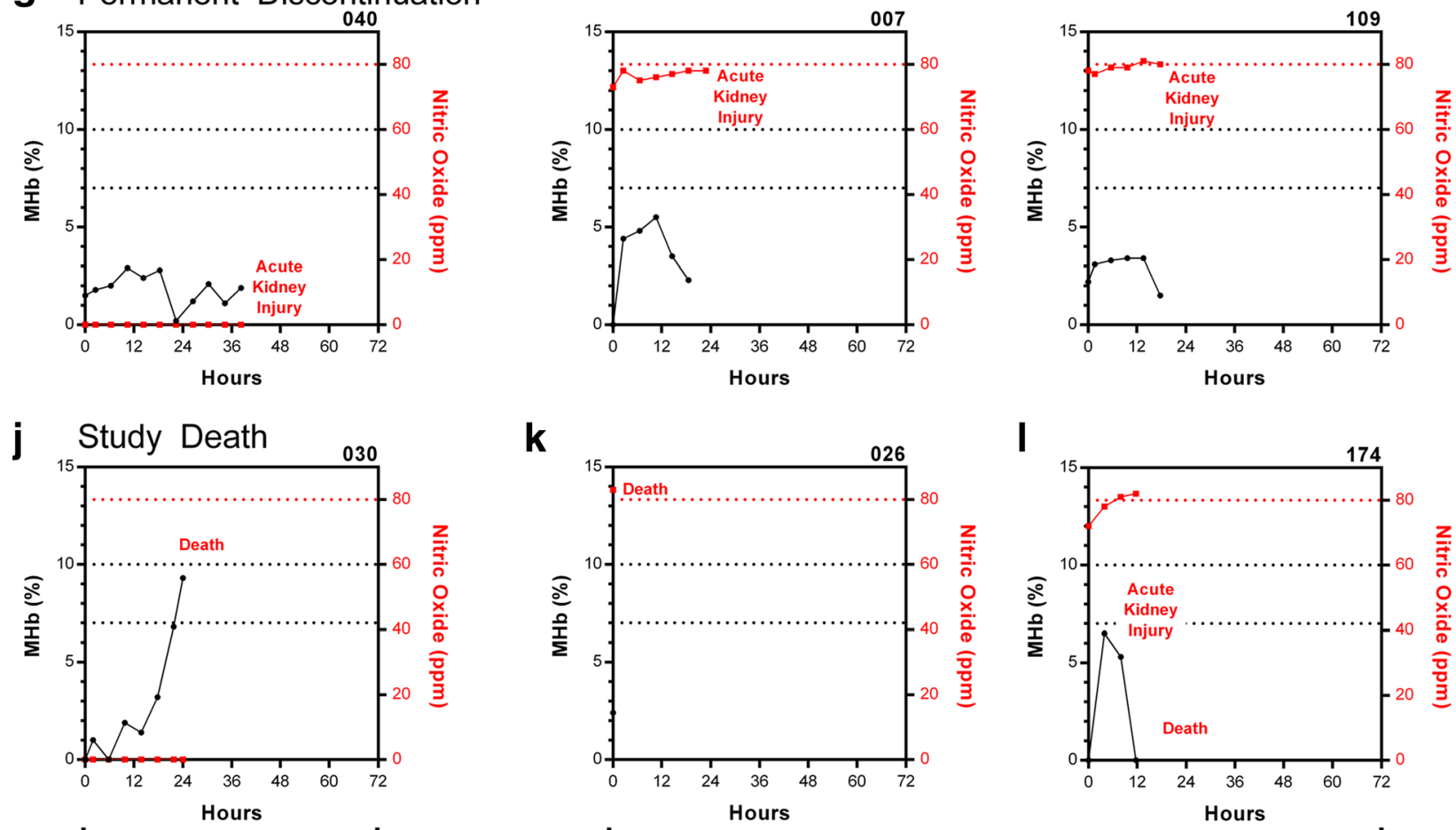

Placebo

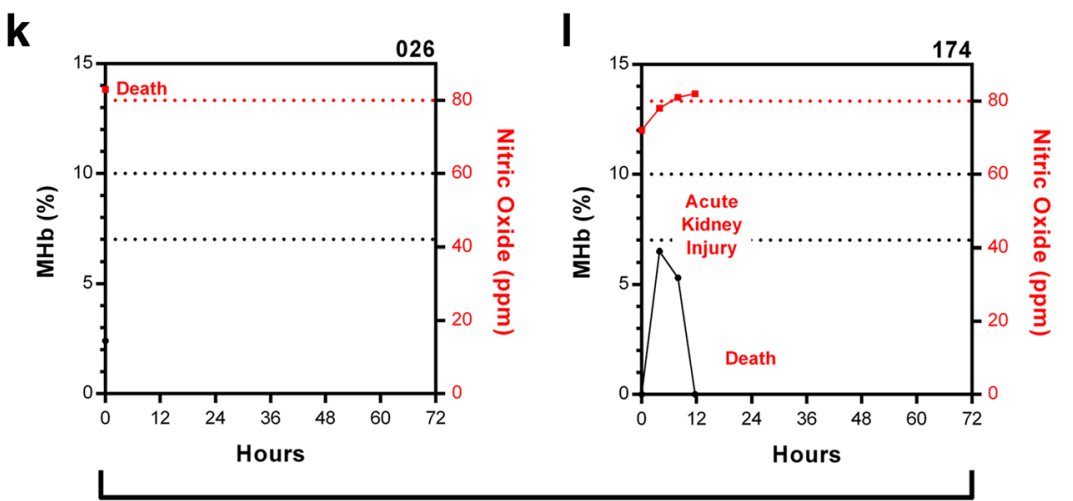

Nitric Oxide

Fig. 2 Representative graphs of methemoglobin kinetics and nitric oxide concentrations administered to children with severe malaria over hospitalization. a, b, c Representative plots from children receiving study gas with no interruptions to study gas. $\mathbf{d}, \mathbf{e}, \mathbf{f}$ Graphs showing MHb kinetics in children with a temporary interruption to study gas administration. $\mathbf{g}, \mathbf{h}, \mathbf{i}$ Graphs from children who had study gas permanently discontinued because they met criteria for acute kidney injury. $\mathbf{j}, \mathbf{k}, \mathbf{l}$, Graphs from non-survivors 
causes of fever, whereas all children in the iNO RCT had a diagnosis of severe malaria.

Among children enrolled in the fever cohort, there were no differences in MHb levels based on demographic characteristics (age, sex, or nutritional status). Infants less than 6 months represent a vulnerable group for methemoglobinemia for a number of reasons, including: a higher $\mathrm{pH}$ in the stomach that permits the growth of nitrate-reducing organisms (e.g. Escherichia coli, Salmonella spp.); immature NADH-methemoglobin reductase systems with reduced capacity to cope with oxidative stress (levels at birth are only $50-60 \%$ of adult levels) $[18,25,26]$; the presence of fetal hemoglobin which is more readily oxidized to $\mathrm{MHb}$ than adult $\mathrm{Hb}$ [18]; and a higher consumption of water per unit body weight, which renders them susceptible to methemoglobinemia if exposed to nitrates through drinking water [27]. Despite these known risk factors in young children, we did not observe an age-dependent effect on MHb levels in our population of children hospitalized with fever.

Given the high rate of methemoglobinemia in our cohort (34 \% of children in the fever cohort had MHb $>2 \%$ ), Ugandan children may be at higher risk for methemoglobinemia than populations from high-resource settings as their environmental exposures may result in a higher set-point for $\mathrm{MHb}$. A common cause of $\mathrm{MHb}$ in children is ingestion or contact with direct or indirect oxidizing agents (e.g. benzocaine, chloroquine, primaquine, sulfonamides, nitrites/nitrates, dapsone). As a result, we explored whether there was an association between known drug exposures (e.g. pretreatments with antibiotics and/or anti-malarials) and MHb levels. There was a non-significant increase in the odds of elevated methemoglobinemia in children that received pretreatment with any antibiotic (Table 2, $p=0.079$ ). Due to the variability in antibiotic prescription and limitations in parental recall, we were limited in our ability to explore relationships between specific classes of drugs and $\mathrm{MHb}$ levels. Furthermore, we were unable to assess environmental exposure to other oxidizing agents in in this population (e.g., nitrates in water, or smoke inhalation through indoor biomass fuel use). However, a study evaluating nitrate levels in spring water from central Uganda reported $60 \%(52 / 80)$ of water samples had nitrate levels exceeding the WHO maximum permissible levels [28]. In addition, widespread reliance on biomass fuel use (e.g., wood) in cooking stoves or open fires contributes to high levels of indoor air pollution [29]. It is estimated that $78 \%$ of the Ugandan population resides in rural areas where $86 \%$ use wood for cooking $[29,30]$. Based on these findings, it is likely that environmental exposure to oxidants in our population exceeds WHO recommended levels.

We explored the association between clinical signs and symptoms at hospital presentation and MHb levels, and observed two general trends. First, children with impaired perfusion and acidosis (vomiting, delayed capillary refill, and elevated lactate) had significantly higher odds of methemoglobinemia after controlling for a set of potential confounders. These findings are consistent with previous studies in infants where methemoglobinemia was reported in the context of metabolic acidosis secondary to diarrhea and dehydration [31, 32]. In our cohort, we observed increased odds of methemoglobinemia associated with vomiting, but not diarrhea. Children with fever and diarrhea alone were excluded from the study. The prevalence of $P$. falciparum parasitemia in this cohort was high at $67 \%$. Therefore, the acidosis observed in this study may be attributable to malaria rather than dehydration and diarrhea, as metabolic acidosis is a common complication of malaria [33-35]. These data suggest that in conditions of increased inflammation, oxidative stress and acidosis, impaired reduction or reconversion of $\mathrm{MHb}$ to $\mathrm{Hb}$ may contribute to the elevated MHb levels observed in our cohort [18, 36, 37].

Methemoglobinemia was also seen in circumstances where red blood cells (RBCs) are affected: severe anemia, children with suspected or documented hemoglobinopathies (i.e. sickle cell disease or G6PD deficiency), and malaria. RBCs are particularly susceptible to oxidative damage as they carry oxygen in high concentrations and are continuously exposed to oxygen free radicals. As RBCs lack a nucleus, they are dependent on endogenous reduction systems that can degrade with repeated exposure to oxidants or RBC senescence [38]. Recent estimates of G6PD polymorphisms in Uganda show $20 \%$ of the population carry the G6PD A-mutation [39], which are consistent with the range of estimates 15-32 \% described elsewhere in Africa [40-42]. With increased oxidative stress on RBCs in G6PD deficiency, sickle cell disease, and other RBC polymorphisms, the capacity of endogenous reduction systems may be overwhelmed leading to increased $\mathrm{MHb}$. In this population, rates of malaria were high with roughly two thirds of children admitted to hospital with fever having parasitologic evidence of malaria infection. Because quantitative estimates of malaria burden (either parasitemia or plasma HRP2 antigen levels) were not available in this cohort, it is difficult to estimate the fraction of fevers in children hospitalized attributable to malaria. Regardless, malaria was independently associated with increased odds of methemoglobinemia (OR (95 \% CI), 1.34 (1.07, 1.69), $p=0.011)$, consistent with previous reports of methemoglobinemia in malaria [43-46]. Malaria is associated with increased oxidative stress from malaria-heme products and immune cell derived reactive oxygen species, both of which could promote oxidation of $\mathrm{Hb}$ to $\mathrm{MHb}[47,48]$. Finally, as children with severe anemia possess compromised oxygen carrying capacity, increased levels of MHb in the context of severe 
anemia may exacerbate reduced oxygen delivery resulting in metabolic acidosis and functional impairments in $\mathrm{MHb}$ reduction. Although elevated $\mathrm{MHb}$ was more common in non-survivors compared to survivors, it is likely that elevated $\mathrm{MHb}$ is a consequence of oxidative stress and acidosis in severe disease rather than mediating severe disease. However, in children with potentially symptomatic levels of $\mathrm{MHb}$ (e.g. the $3 \%$ of children with MHb $>10 \%$ at admission in the fever cohort), MHb could exacerbate underlying disease processes and treatment may be warranted.

In the context of the clinical trial, $11 \%$ of children assessed for eligibility were excluded for methemoglobinemia, which is considerably less than the fever cohort (34\%). The lower prevalence of methemoglobinemia in the iNO RCT may be due to a number of factors, including exclusion of children with known chronic illness (i.e., hemoglobinopathy). Furthermore, children otherwise eligible for the clinical trial were only excluded for methemoglobinemia if their $\mathrm{MHb}$ levels remained $\geq 2 \%$ following stabilization (which included administration of fluids, transfusion in cases of severe anemia, and dextrose to treat/prevent hypoglycemia). As catabolism of sugars through glycolysis is a major source of substrate for the NADH-cytochrome- $b_{5}$ reductase system, glucose levels must be in adequate supply for endogenous $\mathrm{MHb}$ reducing systems to respond [18]. Therefore, these stabilization measures may have contributed to a reduction in $\mathrm{MHb}$ levels in children allowing them to meet the eligibility criteria for the trial.

We were unable to evaluate the dose-dependent effect of iNO on $\mathrm{MHb}$ levels as all children randomized to receive iNO were started at $80 \mathrm{ppm}$. However, this is the largest trial to date to administer iNO at the maximum approved dose and we were able to evaluate the variability in $\mathrm{MHb}$ responses within subjects and the frequency of methemoglobinemia prompting study gas discontinuation. Despite the high doses of iNO administered, study gas was temporarily discontinued only five times for $\mathrm{MHb}>10 \%$ (all children in the iNO group). We were able to re-start study gas for all children that had a MHb measurement that exceeded $10 \%$ once the $\mathrm{MHb}$ returned to $<7 \%$ without having the MHb exceed $10 \%$ again. It was not necessary to wean children off iNO, in contrast to studies administering iNO to neonates with hypoxic respiratory failure, as we did not observe any rebound effects (e.g. worsening oxygenation) following discontinuation of study gas $[23,49]$. Overall, four hourly MHb checks were sufficient for monitoring iNO administration, with more frequent checks implemented in children when $\mathrm{MHb}$ levels approached $7 \%$ so appropriate measures could be taken if levels exceeded 7 or $10 \%$ (e.g. titrate or temporarily discontinue study gas). As seen in Fig. 3b, MHb levels fluctuated considerably within subjects over hospitalization in both trial arms. It is not clear whether these fluctuations

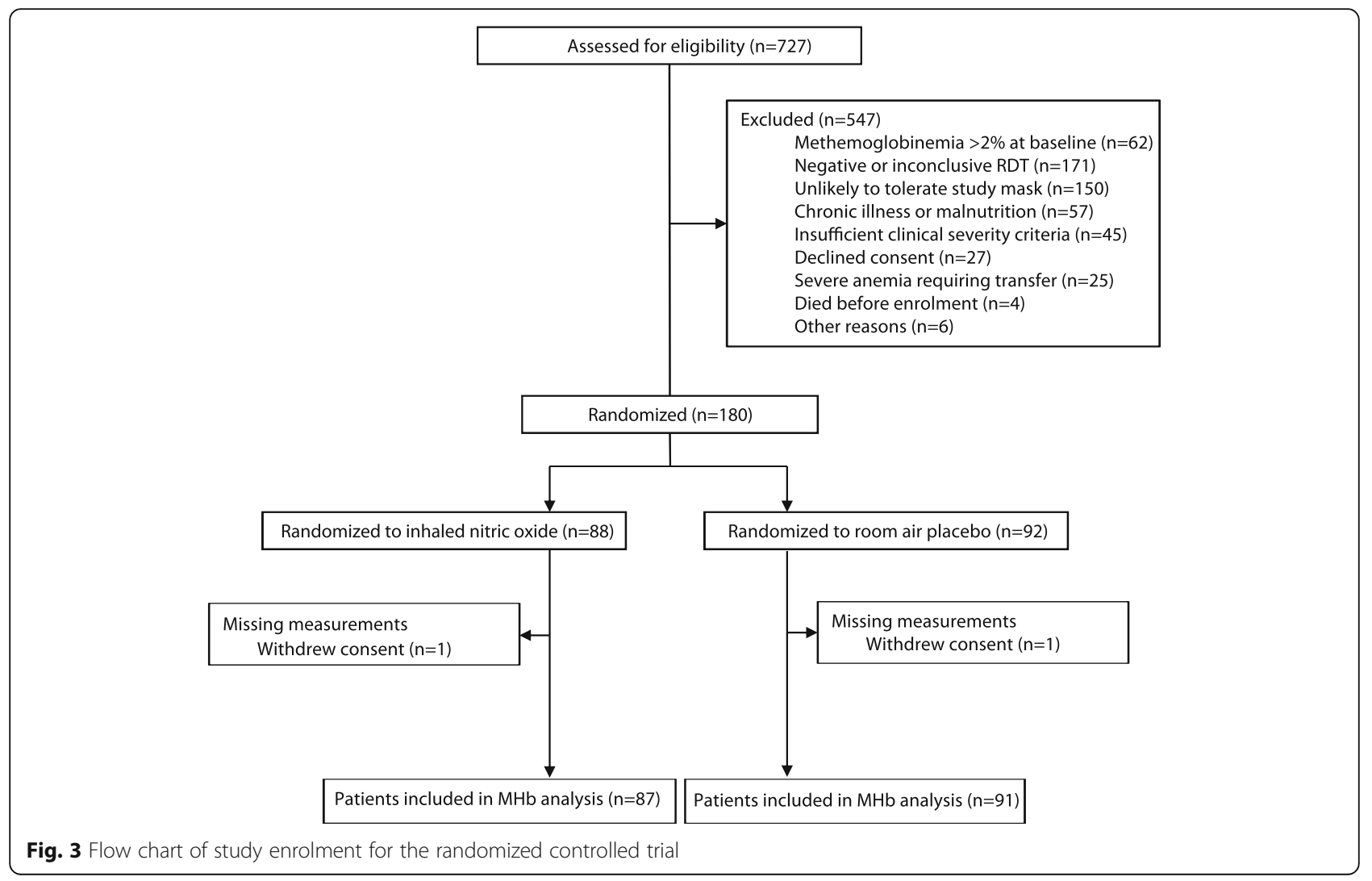


were due to natural variations/regulatory responses in the endogenous reduction systems or were related to $\mathrm{MHb}$ measurement using the pulse co-oximeter. However, performance of non-invasive pulse co-oximetry has been previously compared to whole blood co-oximetry in children with sickle cell disease and showed acceptable clinical accuracy (bias of $-0.22 \%$ for $\mathrm{MHb}$ ) [50]. The variations in $\mathrm{MHb}$ levels over hospitalization highlight the importance of frequent $\mathrm{MHb}$ monitoring during administration of nitric oxide.

When looking at illustrative graphs of MHb kinetics in children with and without study gas interruptions, the variability in responses is apparent (Fig. 1). We specifically included a panel of children who had gas permanently discontinued for acute kidney injury, as administration of iNO has been associated with a statistically elevated risk of developing renal dysfunction in critically ill adults [51]; however, the same association has not been observed in pediatric populations. In a recent retrospective analysis of acute kidney injury in this cohort, we found iNO was associated with an increased risk of acute kidney injury compared to placebo with a relative risk of 1.36 (95\% CI, 1.03$1.80), p=0.026$. We did not observe differences in MHb levels in children who had gas discontinued for acute kidney injury compared to other children. Apart from the one child in the placebo arm of the trial who had increasing MHb levels prior to death, we did not observe elevated $\mathrm{MHb}$ among trial participants who died. However, the majority of participants died early in illness and there were limited kinetic data available. All children except one (Fig. 2l) died in the iNO arm died before repeated $\mathrm{MHb}$ measurements were taken.

After a decade of use in clinical practice, iNO has a wellestablished safety profile. In this study, we administered iNO in a low-resource setting in a non-intensive care setting with limited laboratory support. Using a commercially available handheld pulse co-oximeter, we determined the range of $\mathrm{MHb}$ levels for children admitted to hospital with fever in this population. Although MHb levels $>2 \%$ were observed in $34 \%$ of children admitted with fever, methemoglobinemia was grounds for study exclusion in the iNO RCT for only $11 \%$ of children following stabilization and repeat MHb assessment. In addition, we administered iNO at the highest approved dose in $87 \mathrm{pa}$ tients with severe malaria and had to temporarily discontinue study gas for only a fraction of children (5.7 \%) with $\mathrm{MHb}>10 \%$. Overall, the rates of study gas withdrawal were not different between the placebo and trial arm.

Our study strengths include two integrated studies encompassing a single catchment area: a large prospective observational study to describe MHb levels in children hospitalized with fever, and an intervention where a potent $\mathrm{Hb}$ oxidant was administered and MHb levels assessed. The clinical trial was randomized and double blinded using separate teams to monitor clinical care and study gas administration to ensure clinical decisions to withdraw gas were not affected by intervention. The study gas team used pre-set standard operating procedures to guide decisions regarding titration or withdrawal of study gas. Although we were limited in our ability to report dosedependent effects of iNO on MHb levels, our study is the largest to administer iNO at the maximum approved dose and serves as an important addition to existing literature.

\section{Conclusions}

Methemoglobinemia was a common complication among febrile Ugandan children admitted to hospital, and was associated with vomiting, metabolic acidosis, anemia, red blood cell polymorphisms, and malaria. Among children with severe malaria challenged with high-dose iNO, there was an increase in MHb levels, but rates of gas withdrawal for elevated MHb levels were low. These data suggest that iNO therapy, if clinically warranted, can be administered in low-resource settings provided appropriate monitoring is implemented.

\section{Key messages}

- Methemoglobinemia (MHB >2 \%) was a common feature among febrile Ugandan children admitted to hospital

- Elevated MHb was independently associated with vomiting, prolonged capillary refill time, and metabolic acidosis

- Children with anemia, red blood cell polymorphisms (e.g. sickle cell disease, G6PD deficiency), or malaria had elevated $\mathrm{MHb}$ at admission

- Administration of high-dose (80 ppm) inhaled nitric oxide in children with severe malaria resulted in increased MHb levels that plateaued 12-24 h after study gas initiation

- Inhaled nitric oxide was safe and well-tolerated in critically ill Ugandan children with severe malaria

\section{Abbreviations}

BCS: Blantyre Coma Score; CM: Cerebral malaria; G6PD: Glucose-6-phosphate dehydrogenase; $\mathrm{Hb}$ : Hemoglobin; HRP2: Histidine-rich protein 2; iNO: Inhaled nitric oxide; IQR: Interquartile range; MHb: Methemoglobin; NO: Nitric oxide; OR: Odds ratio; pLDH: Plasmodium Lactate Dehydrogenase; ppm: Parts per million; RBC: Red blood cell; RCT: Randomized controlled trial; RDT: Rapid diagnostic test; SD: Standard deviation; WHO: World Health Organization

\section{Acknowledgments}

We thank all the patients and their families, the medical superintendant of the Jinja Regional Referral Hospital, the many medical officers, nurses and research assistants that cared for the patients and collected study data; Mr. Bruce Murray and Stephen Fairbanks for dedicating their time and technical expertise to the design and maintenance of the nitric oxide delivery system; the Uganda National Council on Science and Technology, the Uganda National Drug Authority, and the Data and Safety Monitoring Board for trial oversight. 


\section{Funding}

Trial operating costs were provided by the Sandra Rotman Centre for Global Health. This work was also supported by a kind donation from Kim Kertland, the Tesari Foundation, the Canadian Institutes of Health Research (CIHR) MOP-244701, MOP-136813, and MOP-13721 [KCK], Canada Research Chair in Molecular Parasitology [KCK], Canada Research Chair in Infectious Diseases and Inflammation [WCL], CIHR Clinician-Scientist Training Award [MH], and Post-Doctoral Research Award [ALC, LH]. The funders had no role in study design, data collection, data analysis, data interpretation, writing of the report, or decision to submit the article for publication. The researchers are independent from the funders.

\section{Availability of data and material}

The datasets during and/or analysed during the current study available from the corresponding author on reasonable request.

\section{Authors' contributions}

The study was conceptualized and designed by KCK with input from ALC, $\mathrm{MH}$ and WCL. Patient recruitment and data collection were obtained by SN, $\mathrm{ROO}, \mathrm{MH}, \mathrm{ALC}, \mathrm{LH}, \mathrm{CRM}, \mathrm{SS}$ and CM. MH and SN supervised clinical care. ALC, LH, CRM and CM were responsible for randomization of study participants, $\mathrm{MHb}$ monitoring, and supervised administration of study gas. Analysis was performed by ALC, with input from $\mathrm{KH}, \mathrm{MH}, \mathrm{CCJ}$, WCL and KCK. ALC, KH, CRM and KCK wrote the manuscript with input from all authors. All authors approved the final version and agree to be accountable for all aspects of the work.

\section{Competing interests}

Dr. Miller is co-founder of Nitric Solutions Inc., and Bovicor Pharmatech Inc. that are developing indications for nitric oxide in human and veterinary medicine, and Dr. Miller is also an inventor on patents related to nitric oxide administration. The other authors declare that they have no competing interests'.

\section{Consent for publication}

Not applicable.

\section{Ethics approval and consent to participate}

Ethical approval was granted from the Uganda National Council for Science and Technology and Makerere University Research Ethics Committee in Uganda, and the Toronto Academic Health Science Network in Canada. Approval from the Uganda National Drug Authority was provided for the clinical trial. Written, informed consent was provided by the accompanying parent or primary caregiver for all study subjects. These studies were conducted according to the Declaration of Helsinki and the ICH guidelines on Good Clinical Practice. A data safety and monitoring board (DSMB) was convened and met periodically to review adverse events, and an interim safety analysis was conducted at the trial midpoint, at which time the DSMB recommended the trial proceed without modifications. Children were eligible to enroll in either the prospective fever cohort or the clinical trial.

\section{Author details}

'Depatment of Medicine, University of Toronto, Toronto, Canada. ${ }^{2}$ Sandra A. Rotman Laboratories, Sandra Rotman Centre for Global Health, University Health Network-Toronto General Hospital, University of Toronto, Toronto, Canada. ${ }^{3}$ Division of Pediatric Infectious Diseases, University of Alberta, Edmonton, Canada. Institute of Medical Sciences, University of Toronto, Toronto, Canada. ${ }^{5}$ Department of Pediatrics, Jinja Regional Referral Hospital, Jinja, Uganda. ${ }^{6}$ Department of Paediatrics and Child Health, Mulago Hospital, Makerere University, Kampala, Uganda. ${ }^{7}$ Department of Pediatrics, Indiana University School of Medicine, Indianapolis, IN, USA. ${ }^{8}$ Department of Medicine, University of Washington, Seattle, WA 98195, USA. ${ }^{9}$ Department of Respiratory Medicine, Faculty of Medicine, University of British Columbia, Vancouver, Canada. ${ }^{10}$ Tropical Disease Unit, Division of Infectious Diseases, Department of Medicine, University of Toronto, Toronto, Canada. ${ }^{11}$ MaRS Centre, TMDT, 10th floor 10-351, Toronto, ON M5G1L7, Canada.

Received: 12 August 2015 Accepted: 25 October 2016 Published online: 04 November 2016

\section{References}

1. Murray CJ, Rosenfeld LC, Lim SS, Andrews KG, Foreman KJ, Haring D, Fullman N, Naghavi M, Lozano R, Lopez AD. Global malaria mortality between 1980 and 2010: a systematic analysis. Lancet. 2012;379(9814):413-31.

2. John CC, Kutamba E, Mugarura K, Opoka RO. Adjunctive therapy for cerebral malaria and other severe forms of Plasmodium falciparum malaria. Expert Rev Anti-Infect Ther. 2010;8(9):997-1008.

3. Higgins SJ, Kain KC, Liles WC. Immunopathogenesis of falciparum malaria: implications for adjunctive therapy in the management of severe and cerebral malaria. Expert Rev Anti Infect Ther. 2011;9(9):803-19.

4. Page AV, Liles WC. Biomarkers of endothelial activation/dysfunction in infectious diseases. Virulence. 2013:4(6):507-16.

5. Griffiths MJ, Evans TW. Inhaled nitric oxide therapy in adults. N Engl J Med. 2005;353(25):2683-95.

6. Hobbs MR, Udhayakumar V, Levesque MC, Booth J, Roberts JM, Tkachuk AN, Pole A, Coon H, Kariuki S, Nahlen BL, et al. A new NOS2 promoter polymorphism associated with increased nitric oxide production and protection from severe malaria in Tanzanian and Kenyan children. Lancet. 2002;360(9344):1468-75.

7. Cramer JP, Nussler AK, Ehrhardt S, Burkhardt J, Otchwemah RN, Zanger P, Dietz E, Gellert S, Bienzle U, Mockenhaupt FP. Age-dependent effect of plasma nitric oxide on parasite density in Ghanaian children with severe malaria. Trop Med Int Health. 2005;10(7):672-80.

8. Anstey NM, Weinberg JB, Hassanali MY, Mwaikambo ED, Manyenga D, Misukonis MA, Arnelle DR, Hollis D, McDonald MI, Granger DL. Nitric oxide in Tanzanian children with malaria: inverse relationship between malaria severity and nitric oxide production/nitric oxide synthase type 2 expression. J Exp Med. 1996;184(2):557-67.

9. Gramaglia I, Sobolewski P, Meays D, Contreras R, Nolan JP, Frangos JA, Intaglietta M, van der Heyde HC. Low nitric oxide bioavailability contributes to the genesis of experimental cerebral malaria. Nat Med. 2006;12(12):1417-22.

10. Serghides L, Kim H, Lu Z, Kain DC, Miller C, Francis RC, Liles WC, Zapol WM, Kain KC. Inhaled nitric oxide reduces endothelial activation and parasite accumulation in the brain, and enhances survival in experimental cerebral malaria. PLOS ONE. 2011;6(11):e27714.

11. Finer NN, Barrington KJ. Nitric oxide for respiratory failure in infants born at or near term. Cochrane Database Syst Rev. 2006;4:CD000399.

12. Barrington KJ, Finer NN. Inhaled nitric oxide for respiratory failure in preterm infants. Cochrane Database Syst Rev. 2006;1:CD000509.

13. Hawkes M, Opoka RO, Namasopo S, Miller C, Thorpe KE, Lavery JV, Conroy AL, Liles WC, John CC, Kain KC. Inhaled nitric oxide for the adjunctive therapy of severe malaria: protocol for a randomized controlled trial. Trials. 2011;12:176.

14. Hawkes M, Opoka RO, Namasopo S, Miller C, Conroy AL, Serghides L, Kim H, Thampi N, Liles WC, John CC, et al. Nitric oxide for the adjunctive treatment of severe malaria: hypothesis and rationale. Med Hypotheses. 2011;77(3):437-44.

15. Weinberger B, Laskin DL, Heck DE, Laskin JD. The toxicology of inhaled nitric oxide. Toxicol Sci. 2001:59(1):5-16.

16. Ashurst J, Wasson M. Methemoglobinemia: a systematic review of the pathophysiology, detection, and treatment. Del Med J. 2011;83(7):203-8.

17. Jaffe ER, Hultquist DE. Cytochrome b5 reductase deficiency and enzymopenic hereditary methemoglobinemia. In: The Metabolic and Molecular Basis of Inherited Diseases. New York: McGraw-Hill; 1995. p. 2267-80.

18. Wright RO, Lewander WJ, Woolf AD. Methemoglobinemia: etiology, pharmacology, and clinical management. Ann Emerg Med. 1999;34(5):646-56.

19. Okello PE, Van Bortel W, Byaruhanga AM, Correwyn A, Roelants P, Talisuna A, D'alessandro U, Coosemans M. Variation in malaria transmission intensity in seven sites throughout Uganda. AmJTrop Med Hyg. 2006;75(2):219-25.

20. Idro R, Aloyo J, Mayende L, Bitarakwate E, John CC, Kivumbi GW. Severe malaria in children in areas with low, moderate and high transmission intensity in Uganda. Trop Med Int Health. 2006;11(1):115-24.

21. Hawkes M, Conroy AL, Opoka RO, Namasopo S, Liles WC, John CC, Kain KC. Use of a three-band HRP2/pLDH combination rapid diagnostic test increases diagnostic specificity for falciparum malaria in Ugandan children. Malar J. 2014;13:43.

22. Dondorp AM, Fanello Cl, Hendriksen IC, Gomes E, Seni A, Chhaganlal KD, Bojang K, Olaosebikan R, Anunobi N, Maitland K, et al. Artesunate versus quinine in the treatment of severe falciparum malaria in African children (AQUAMAT): an open-label, randomised trial. Lancet. 2010;376(9753):1647-57. 
23. Clark RH, Kueser TJ, Walker MW, Southgate WM, Huckaby JL, Perez JA, Roy BJ, Keszler M, Kinsella JP. Low-dose nitric oxide therapy for persistent pulmonary hypertension of the newborn. Clinical Inhaled Nitric Oxide Research Group. N Engl J Med. 2000;342(7):469-74.

24. Hawkes MT, Conroy AL, Opoka RO, Hermann L, Thorpe KE, McDonald C, Kim H, Higgins S, Namasopo S, John C, Miller C, Liles WC, Kain KC. Inhaled nitric oxide as adjunctive therapy for severe malaria: a randomized controlled trial. Malaria J. 2015;14:421.

25. Hjelt K, Lund JT, Scherling B, Bendixen S, Lundstrom K, Stovring S, Voldsgaard P, Linnet K. Methaemoglobinaemia among neonates in a neonatal intensive care unit. Acta Paediatr. 1995;84(4):365-70.

26. Panin G, Pernechele M, Giurioli R, Secchieri S, Milanesi O, Pellegrino PA, Chiandetti L. Cytochrome b5 reductase activity in erythrocytes and leukocytes as related to sex and age. Clin Chem. 1984;30(5):701-3.

27. Gupta SK, Gupta RC, Seth AK, Gupta AB, Bassin JK, Gupta A. Adaptation of cytochrome-b5 reductase activity and methaemoglobinaemia in areas with a high nitrate concentration in drinking-water. Bull World Health Organ. 1999;77(9):749-53.

28. Haruna R, Ejobi F, Kabagambe EK. The quality of water from protected springs in Katwe and Kisenyi parishes, Kampala city, Uganda. Afr Health Sci. 2005;5(1):14-20

29. van Gemert F, Chavannes N, Nabadda N, Luzige S, Kirenga B, Eggermont C, de Jong $C$, van der Molen T. Impact of chronic respiratory symptoms in a rural area of sub-Saharan Africa: an in-depth qualitative study in the Masindi district of Uganda. Prim Care Respir J. 2013;22(3):300-5.

30. Male-Mukasa JB. Uganda National Household Survey. Uganda Bureau of Statistics; 2010. (http://www.ubos.org/UNHS0910/unhs200910.pdf).

31. Pollack ES, Pollack Jr CV. Incidence of subclinical methemoglobinemia in infants with diarrhea. Ann Emerg Med. 1994;24(4):652-6.

32. Yano SS, Danish EH, Hsia YE. Transient methemoglobinemia with acidosis in infants. J Pediatr. 1982;100(3):415-8.

33. Taylor TE, Borgstein A, Molyneux ME. Acid-base status in paediatric Plasmodium falciparum malaria. Q J Med. 1993;86(2):99-109.

34. Krishna S, Waller DW, ter Kuile F, Kwiatkowski D, Crawley J, Craddock CF, Nosten F, Chapman D, Brewster D, Holloway PA, et al. Lactic acidosis and hypoglycaemia in children with severe malaria: pathophysiological and prognostic significance. Trans R Soc Trop Med Hyg. 1994;88(1):67-73.

35. Marsh K, English M, Crawley J, Peshu N. The pathogenesis of severe malaria in African children. Ann Trop Med Parasitol. 1996;90(4):395-402.

36. Shugalei IV, L'Vov SN, Baev VI, Tselinskii IV. Protective effect of sodium bicarbonate in nitrite ion poisoning. Ukr Biokhim Zh. 1994;66(1):109-12.

37. Klurfeld G, Smith RP. Effects of chloride and bicarbonate on methemoglobin reduction in mouse erythrocytes. Biochem Pharmacol. 1968;17(6):1067-77.

38. Bernstein SC, Bowman JE, Noche LK. Interaction of sickle cell trait and glucose-6-phosphate dehydrogenase deficiency in Cameroon. Hum Hered. 1980;30(1):7-11

39. Bwayo D, Kaddumukasa M, Ddungu H, Kironde F. Prevalence of glucose-6 phosphate dehydrogenase deficiency and its association with Plasmodium falciparum infection among children in Iganga distric in Uganda. BMC Res Notes. 2014;7(1):372.

40. Guindo A, Fairhurst RM, Doumbo OK, Wellems TE, Diallo DA. X-linked G6PD deficiency protects hemizygous males but not heterozygous females against severe malaria. PLoS Med. 2007;4(3):e66.

41. Bouanga JC, Mouele R, Prehu C, Wajcman H, Feingold J, Galacteros F. Glucose-6-phosphate dehydrogenase deficiency and homozygous sickle cell disease in Congo. Hum Hered. 1998;48(4):192-7.

42. Mombo LE, Ntoumi F, Bisseye C, Ossari S, Lu CY, Nagel RL, Krishnamoorthy R. Human genetic polymorphisms and asymptomatic Plasmodium falciparum malaria in Gabonese schoolchildren. Am J Trop Med Hyg. 2003;68(2):186-90

43. Yeo TW, Lampah DA, Kenangalem E, Tjitra E, Price RN, Anstey NM. Increased carboxyhemoglobin in adult falciparum malaria is associated with disease severity and mortality. J Infect Dis. 2013;208(5):813-7.

44. Hanscheid T, Gresnigt T, Lohr S, Flamen A, Zoller T, Melo-Cristino J, Grobusch MP. Methaemoglobin and $\mathrm{COHb}$ in patients with malaria. Malar J. 2014;13:285

45. Uko EK, Udoh AE, Etukudoh MH. Methaemoglobin profile in malaria infected children in Calabar. Niger J Med. 2003;12(2):94-7.

46. Anstey NM, Hassanali MY, Mlalasi J, Manyenga D, Mwaikambo ED. Elevated levels of methaemoglobin in Tanzanian children with severe and uncomplicated malaria. Trans R Soc Trop Med Hyg. 1996;90(2):147-51.
47. Nantakomol D, Dondorp AM, Krudsood S, Udomsangpetch R, Pattanapanyasat K, Combes V, Grau GE, White NJ, Viriyavejakul P, Day NPJ, et al. Circulating red cell-derived microparticles in human malaria. J Infect Dis. 2011:203(5):700-6.

48. Charunwatthana P, Abul Faiz M, Ruangveerayut R, Maude RJ, Rahman MR, Roberts 2nd LJ, Moore K, Bin Yunus E, Hoque MG, Hasan MU, et al. $\mathrm{N}$-acetylcysteine as adjunctive treatment in severe malaria: a randomized, double-blinded placebo-controlled clinical trial. Crit Care Med. 2009;37(2):516-22.

49. Neonatal Inhaled Nitric Oxide Study G. Inhaled nitric oxide in full-term and nearly full-term infants with hypoxic respiratory failure. N Engl J Med. 1997;336(9):597-604.

50. Caboot JB, Jawad AF, McDonough JM, Bowdre CY, Arens R, Marcus CL, Mason TB, Smith-Whitley K, Ohene-Frempong K, Allen JL. Non-invasive measurements of carboxyhemoglobin and methemoglobin in children with sickle cell disease. Pediatr Pulmonol. 2012;47(8):808-15.

51. Adhikari NK, Burns KE, Friedrich JO, Granton JT, Cook DJ, Meade MO. Effect of nitric oxide on oxygenation and mortality in acute lung injury: systematic review and meta-analysis. BMJ. 2007;334(7597):779.

52. Hawkes M, Conroy AL, Opoka RO, Namasopo S, Liles WC, John CC, Kain KC. Performance of point-of-care diagnostics for glucose, lactate, and hemoglobin in the management of severe malaria in a resource-constrained hospital in Uganda. Am J Trop Med Hyg. 2014;90(4):605-8.

\section{Submit your next manuscript to BioMed Central and we will help you at every step:}

- We accept pre-submission inquiries

- Our selector tool helps you to find the most relevant journal

- We provide round the clock customer support

- Convenient online submission

- Thorough peer review

- Inclusion in PubMed and all major indexing services

- Maximum visibility for your research

Submit your manuscript at www.biomedcentral.com/submit
) Biomed Central 